\title{
On the Origins of Cultural Differences in Conformity: Four Tests of the Pathogen Prevalence Hypothesis
}

\author{
Damian R. Murray', Russell Trudeau', and Mark Schaller'
}

\begin{abstract}
What are the origins of cultural differences in conformity? The authors deduce the hypothesis that these cultural differences may reflect historical variability in the prevalence of disease-causing pathogens: Where pathogens were more prevalent, there were likely to emerge cultural norms promoting greater conformity. The authors conducted four tests of this hypothesis, using countries as units of analysis. Results support the pathogen prevalence hypothesis. Pathogen prevalence positively predicts cultural differences in effect sizes that emerge from behavioral conformity experiments $(r=.49, n=17)$ and in the percentage of the population who prioritize obedience $(r=.48, n=83)$. Pathogen prevalence also negatively predicted two indicators of tolerance for nonconformity: within-country dispositional variability $(r=-.48, n=33)$ and the percentage of the population who are left-handed $(r=-.73, n=20)$. Additional analyses address plausible alternative causal explanations. Discussion focuses on plausible underlying mechanisms (e.g., genetic, developmental, cognitive).
\end{abstract}

\section{Keywords}

conformity, culture, disease, obedience, pathogen prevalence

Received February 4, 2010; revision accepted October 4, 2010

Humans value conformist behavior of many kinds. People are typically expected to comply with social norms and may suffer considerable social costs for behavioral deviance. Obedience, a more specific type of conformity, is also valued: Children are expected to obey the directives of their parents and other authority figures and are often punished if they don't. Conversely, however, humans also value various forms of deviance. People are often celebrated for generating novel, counternormative ideas or for resisting the directives of authority figures.

The essential tension between conformity and deviance is resolved differently in different human cultures. In one recent wave of the World Values Survey, barely 5\% of respondents in Japan indicated that obedience was an especially important quality for children to learn, whereas in India and Mexico the corresponding percentage was more than $50 \%$. In a meta-analysis of conformity experiments (Bond \& Smith, 1996), the mean conformity effect size was relatively modest in countries such as France and Portugal but more than twice as high in places such as Brazil, Hong Kong, and Zimbabwe. In short, there are considerable cross-cultural differences in conformity-relevant attitudes and behavior. However, the origins of those differences remain unclear. Exactly why might these cross-cultural differences exist in the first place?
Various processes are likely to contribute to these crosscultural differences. There is evidence to suggest that some cultural differences in conformity-relevant constructs (e.g., attitudes promoting independence in thought and action) may have resulted, in part, from selective patterns of human migration and settlement (Kitayama \& Bowman, 2010; Kitayama, Ishii, Imada, Takemura, \& Ramaswamy, 2006). Other perspectives emphasize the role of ecological and/or economic variability (e.g., Cohen, 2001; Van de Vliert, 2009). For instance, Berry $(1967,1979)$ suggested a causal link between mode of subsistence and conformity, with the implication that, compared to traditional economies based on hunting and fishing, economies based on agricultural practices are likely to promote higher levels of obedience and conformity.

The present research complements those conceptual perspectives and focuses on an ecological variable that has not previously received attention within the conformity literature: the threat posed by infectious diseases. By considering

\footnotetext{
'University of British Columbia, Vancouver, Canada

Corresponding Author:

Damian R. Murray, University of British Columbia, Department of Psychology, 2136 West Mall, Vancouver BC V6T IZ4, Canada Email: dmurray@psych.ubc.ca
} 
functionally adaptive behavioral responses to the threat of infectious disease, we deduce the following hypothesis: Under ecological conditions characterized by a higher prevalence of disease-causing pathogens, there are likely to emerge cultural norms promoting greater conformity. Then, employing a diverse array of measures (based on both survey results and behavioral observations) that assess country-level indicators of conformity, we report four sets of results that provide the first direct empirical tests of this hypothesis.

\section{Disease Threat, Adaptive Behavior, and Cultural Variability}

Infectious diseases have historically posed a substantial threat to human health and fitness (Hurtado, Frey, Hill, Hurtado, \& Baker, 2008; Wolfe, Dunavan, \& Diamond, 2007). As a consequence, humans are characterized by a variety of defenses that mitigate the threat posed by disease-causing pathogens. These defenses include the suite of physiological mechanisms that compose the immune system. In addition, much research indicates that humans, as well as other animals, are characterized also by a sort of behavioral immune system - a suite of psychological mechanisms that promote specific kinds of behavioral responses that inhibit contact with, and inhibit transmission of, infectious diseases (e.g., Duncan \& Schaller, 2009; Kavaliers \& Colwell, 1995; Kiesecker, Skelly, Beard, \& Preisser, 1999; Oaten, Stevenson, \& Case, 2009; Park, Faulkner, \& Schaller, 2003; Park, Schaller, \& Crandall, 2007; Schaller \& Duncan, 2007; Schaller \& Park, in press). An important finding to have emerged from this literature is that disease-avoidant cognitive and behavioral responses vary in strength, depending on individuals' perceived vulnerability to infectious diseases. For example, aversive responses to foreign peoples appear to result, in part, from the operation of disease-avoidant processes. Accordingly, xenophobic and ethnocentric responses are exaggerated under conditions in which the apparent threat of disease is also exaggerated (Faulkner, Schaller, Park, \& Duncan, 2004; Navarrete \& Fessler, 2006; Navarrete, Fessler, \& Eng, 2007). Extraversion provides another illustrative example. Compared to introversion, extraversion poses a greater risk of pathogen infection, given that extraversion is typically characterized by increased interpersonal contact. Accordingly, when the threat of pathogen transmission is especially salient, people exhibit lower levels of extraversion, in both self-reports and actual behavior (Mortensen, Becker, Ackerman, Neuberg, \& Kenrick, 2010).

Just as individual behavior varies predictably in response to the salience of disease in the immediate perceptual environment, collective behavioral tendencies (of the kind that define cultural norms) may vary predictably in response to the prevalence of disease-causing pathogens in the local ecology. This speculation is informed by a conceptual analysis that considers how pathogen prevalence influences the relative costs and benefits associated with specific behavioral tendencies. Extraversion again provides an illustrative example. In a social species such as humans, extraverted behavior is associated with many functionally beneficial consequences, but it also is associated with increased risk of pathogen infection. These disease-specific costs are greater (and therefore are increasingly likely to outweigh the functional benefits of extraversion) under circumstances in which the actual prevalence of disease-causing pathogens is also greater. To the extent that human behaviors (and cultural norms defined by human behaviors) are responsive to these relative costs and benefits, the implication is a causal relation between ecological variability in pathogen prevalence and cultural variability in extraversion. Cross-national data on extraversion support this hypothesis: Across multiple measures obtained from thousands of participants in dozens of countries, mean country-level scores on extraversion are negatively correlated with country-level indicators of pathogen prevalence (Schaller \& Murray, 2008). Additional analyses reported by Schaller and Murray (2008) show that these relationships remain even when controlling for a variety of additional country-level variables.

The use of culinary spices provides another useful example. There are costs associated with the cultivation and use of spices, but there are specific disease-related benefits as well: Spices are natural antibiotics, and because of these antibiotic properties, their use in food preparation is functionally beneficial (Billing \& Sherman, 1998). These antibiotic benefits are more likely to outweigh the costs under ecological circumstances characterized by a higher prevalence of bacterial pathogens. The implication, at a cultural level of analysis, is that the use of spices in food preparation should be a positive function of the prevalence of pathogens within the local ecology. Empirical evidence reveals that this is indeed the case: Where pathogens are more prevalent, people traditionally use more spices when preparing food (Murray \& Schaller, 2010; Sherman \& Billing, 1999).

Similar cost/benefit analyses have been applied to many other kinds of cultural variation as well. Empirical evidence links pathogen prevalence not only to cultural variability in personality traits and culinary practices but also to variability in mating preferences, family structures, intergroup behavior, social values, and political ideologies (Fincher, Thornhill, Murray, \& Schaller, 2008; Gangestad, Haselton, \& Buss, 2006; Letendre, Fincher, \& Thornhill, 2010; Low, 1990; Murray \& Schaller, 2010; Quinlan, 2007; Schaller \& Murray, 2008; Schaller \& Murray, 2010; Thornhill, Fincher, \& Aran, 2009).

\section{Pathogen Prevalence and Conformity}

There are logical implications for cultural variability in conformity too. There are potential benefits associated with behaviors that deviate from existing norms. Some benefits are observed in mating contexts, and men in particular appear 
to strategically nonconform to distinguish themselves for the purposes of attracting a mate (Griskevicius, Goldstein, Mortensen, Cialdini, \& Kenrick, 2006). Other benefits include the many useful innovations and novel discoveries that arise when individuals perform tasks in novel, non-normative ways. This implies a set of costs - both to individuals and to societies-associated with cultural values emphasizing obedience and conformity (e.g., decreased incidence of useful innovations).

These costs, however, must be weighed against the benefits associated with behavior that conforms to existing cultural rituals and norms. Living in large groups requires some degree of behavioral coordination and conformity (Henrich, 2003). Furthermore, many cultural rituals and norms exist, and persist, because they mitigate threats that exist within the local ecology - including the threat posed by infectious diseases. Social norms in the realm of food preparation, personal hygiene, and public health-such as traditional uses of culinary spices or normative proscriptions against defecation in the proximity of drinking water sources - provide buffers against pathogen transmission. So do normative guidelines governing social interaction (e.g., cultural rules limiting interactions with foreigners and other unknown peoples). If individuals deviate from these social norms (and fail to obey parents and other authority figures who communicate normative expectations), they expose themselves and others to increased risk of pathogen infection. If individuals conform to these social norms, pathogen transmission is reduced.

Conformity thus offers specific disease-related benefits that must be weighed against its costs. These benefits, of course, increase as a function of the actual baseline risk of pathogen transmission, which is a direct function of pathogen prevalence in the local ecology. Deviating from normative methods of food preparation, for example, is likely to be more costly in regions characterized by a higher prevalence of pathogens, whereas in regions of low pathogen prevalence, the cost may be outweighed by the benefits that accrue from innovation. There are multiple mechanisms through which individual actions and societal norms may be influenced by costs and benefits, and we articulate these mechanisms in greater detail in the discussion, below. Regardless of the exact underlying mechanism(s), however, the implication is a hypothesized causal relationship between pathogen prevalence and cross-cultural variability in conformity: Under ecological circumstances historically characterized by higher levels of pathogen prevalence, there are likely to emerge cultures that are more strongly characterized by conformist values and behaviors.

Some recent empirical evidence bears on this hypothesis, but only obliquely. In research on cultural variability in personality traits, it has been found that pathogen prevalence is negatively correlated not only with extraversion but also with openness to experience (Schaller \& Murray, 2008). In research focusing on cultural values, it has been found that pathogen prevalence correlates negatively with individualism and positively with collectivism (Fincher et al., 2008). However, none of these findings bears directly on conformity. Openness and individualism/collectivism are exceptionally broad, multifaceted constructs. Some of these underlying facets are conceptually relevant to conformity, but many are not. Thus, it is not at all clear whether or not their relationships with pathogen prevalence reflect on the current hypothesis. Openness is characterized in part by a willingness to entertain novel thoughts and ideas, but it is more broadly defined by dispositions pertaining to artistic interests, emotional experiences, fantasy, and intellect - all of which are conceptually distinct from conformity. Indeed, the three openness measures employed by Schaller and Murray (2008) show modest correlations with both Bond and Smith's (1996) conformity effect sizes ( $r$ s ranging from -.28 to -.64 ) and with the World Values Survey's value placed on obedience ( $r$ s ranging from .01 to -.32 ) Similarly, although collectivism is characterized in part by an emphasis on traditionalism, it is also defined by many additional culturallevel variables that are conceptually unrelated to conformity (closer family ties, stronger ingroup/outgroup boundaries, higher levels of xenophobia, etc.). The four individualism/ collectivism measures employed by Fincher et al. (2008) also show modest correlations with conformity effect size (absolute $r$ s ranging from .36 to .63) and with value placed on obedience (absolute $r$ s ranging from .25 to .51). Indeed, explanations for the relationship between pathogen prevalence and collectivism have tended to focus especially on family dynamics and intergroup attitudes (e.g., Fincher \& Thornhill, 2008; Thornhill et al., 2009). Thus, although research on these higher-order constructs has produced findings that are loosely consistent with the hypothesized link between pathogen prevalence and conformity, the majority of the variance across cultures in conformity-related measures remains unexplained, and no previous results have provided a direct rigorous test of the pathogen prevalence hypothesis.

\section{Overview of the Present Investigation}

The results reported below provide four separate tests of the hypothesis. As with much recent cross-cultural research in the psychological sciences, we employed contemporary geopolitical boundaries as a proxy for boundaries between different cultural populations. Consequently, geopolitical regions (countries) served as the unit of analysis. For each country, we obtained a measure indicating the historical prevalence of disease-causing pathogens. Statistical analyses tested the extent to which pathogen prevalence correlated, as hypothesized, with country-level differences in conformity.

Each test of the hypothesis employed a methodologically distinct index of within-country conformity pressure. Two of the four tests employed straightforward measures of conformity pressure: effect sizes emerging from Asch-style 
behavioral experiments assessing conformity to majority opinion (data available for 17 countries) and percentages of survey respondents who indicated that obedience is an especially important value for children to learn (data available for 83 countries). Two additional tests focused on country-level outcomes that reflect cultural tolerance for nonconformity. One of these tests follows from the logical implication that, in cultures characterized by stronger conformity pressure, there is reduced tolerance for dispositional tendencies that deviate from local dispositional norms. Consequently, tolerance for nonconformity is reflected by within-country variability around mean values on basic personality traits (data available for 33 countries). A fourth measure focused on handedness. In his pioneering work on cultural "tightness" (a construct that overlaps substantially with conformity pressure; Gelfand, Nishii, \& Raver, 2006), Harry Triandis (1995) observed that "in all cultures the right hand is considered the correct one, but in cultures that are tight there is pressure for those who are naturally left-handed to become right-handed" (p. 56; also see Fagard \& Dahmen, 2004; Porac \& Martin, 2007). Consequently, tolerance for nonconformity is reflected by the relative percentage of left-handed people within a population (data from 20 countries).

The pathogen prevalence hypothesis yields the prediction that historically higher levels of pathogen prevalence should be positively correlated with the two measures assessing conformity pressure and negatively correlated with the two measures reflecting tolerance for nonconformity.

The empirical methods are necessarily correlational, but the conceptual hypotheses are causal. Therefore, in addition to the primary analyses testing the pathogen prevalence hypothesis, we also conducted a series of additional analyses designed to address plausible alternative causal explanations.

\section{Method}

\section{Pathogen Prevalence}

Murray and Schaller (2010) provide numerical estimates of the historical prevalence of pathogens within each of 230 geopolitical regions worldwide. Most of these geopolitical regions are countries, although some are colonies, territories, or culturally distinct regions within a country. For expository ease, we use the word country to refer to all these geopolitical regions. The pathogen prevalence index was based on data recorded primarily in the early 1900s that were reported in old epidemiological atlases. Employing these data, Murray and Schaller (2010) assessed the prevalence of nine different disease-causing pathogens (leishmania, schistosoma, trypanosoma, leprosy, malaria, typhus, filaria, dengue, and tuberculosis) within each country and then computationally combined these prevalence scores to create an overall index of historical pathogen prevalence within each country (see Murray \& Schaller, 2010, for complete assessment and computational details and for empirical results attesting to the reliability and validity of this measure as an index of overall pathogen prevalence).

Because of lacunae in the old epidemiological atlases, data on all nine pathogens were not available for all 230 countries. Consequently, Murray and Schaller (2010) report both a nine-item index for 160 countries and a seven-item index for all 230 countries. The two indices are computed on standardized measurement scales. For our analyses, we employed the nine-item pathogen prevalence scores whenever possible; in rare cases that a nine-item score was not available for a country, we employed the seven-item pathogen prevalence score instead.

\section{Test I: Behavioral Conformity Effect Size}

Bond and Smith (1996) conducted a meta-analysis on 133 experiments that used comparable methods assessing behavioral conformity to majority opinion. For each of the 133 experiments included in their analysis, Bond and Smith (1996) report the conformity effect size that emerged in its results as well as the country in which it was conducted. Results from 17 countries were reported. For each of these 17 countries, we computed the mean effect size from all of the experiments performed within that country.

\section{Test 2: Percentage of Population Who Prioritize Obedience}

Since 1990, four waves of the World Values Survey have been completed. As part of this massive cross-national survey, hundreds of thousands of people, in 83 different countries, have been presented with the following survey question: "Here is a list of qualities that children can be encouraged to learn at home. Which, if any, do you consider to be especially important?" Respondents are presented with a list of 10 different qualities to choose from (obedience, hard work, religious faith, feeling of responsibility, imagination, independence, tolerance and respect for other people, thrift/saving money and things, determination/perseverance, unselfishness). They have been asked to choose "up to five" qualities that they consider especially important. Survey results are electronically available (www.worldvaluessurvey.org). Drawing on all waves of data collection that had been completed in each country from 1990 to 2005 , we computed, for each country, the percentage of respondents who indicated that "obedience" was an especially important quality for children to learn.

\section{Test 3: Dispositional Variability}

McCrae (2002) summarized results from multiple independent studies that used the NEO-PI-R questionnaire to assess self-reported personality traits in 33 different countries. The NEO-PI-R results are summarized in terms of 5 fundamental 
personality dimensions (the Big Five: agreeableness, conscientiousness, extraversion, neuroticism, and openness), each of which is further composed of 6 facet scores. For each of these 30 facets, McCrae computed within-country means (on a standardized scale of measurement), as well as standard deviations around those means, and further computed the mean of these 30 facet-level standard deviations. Lower values on this "mean standardized standard deviation" (McCrae, 2002, Table 3) indicate greater within-country homogeneity in dispositional tendencies. Conversely, high values indicate a greater tendency for individuals' dispositional tendencies to deviate from the within-country norm and thus indicate greater cultural tolerance for nonconformity. (Country-level means on the Big Five traits were modestly correlated with this measure of dispositional variability. Therefore, we statistically controlled for mean trait levels by focusing our analyses on a residual value of dispositional variability, from which any statistical overlap with mean trait levels was removed. Inferentially identical results were obtained in analyses in which mean trait levels were left uncontrolled.)

\section{Test 4: Percentage of Population Who Are Left-Handed}

Within the laterality literature, there is considerable variability in the methods employed to assess handedness. To limit noise because of method variance, we limited our analysis to the results of studies that employed the same methods used by Perelle and Ehrman (1994). Perelle and Ehrman conducted the largest systematic, cross-national handedness survey to date (data from more than 11,000 people). Among their results, they report, for each of 13 countries, the percentage of respondents who categorized themselves as either moderately or strongly left-handed. To supplement these results, we searched the laterality literature for additional studies that employedin additional countries - the same assessment tools and reporting methods as Perelle and Ehrman. This literature search yielded methodologically comparable handedness data for 7 additional countries. For each of the 20 countries in our analysis, therefore, we computed the percentage of respondents who categorized themselves as being predominantly left-handed. Higher percentages of left-handers reflect a greater cultural tolerance for nonconformity.

\section{Ancillary Analyses and Additional Variables}

Although geopolitical boundaries serve as useful proxies for cultural boundaries, it can be argued that many countries (especially neighboring countries) are neither ecologically nor culturally independent and therefore do not constitute statistically independent units of analysis. This nonindependence poses interpretational problems for country-level data and potentially inflates the magnitude of correlations between country-level variables (Ross \& Homer, 1976). Consequently, to complement our primary (country-level) analyses, we conducted a second set of analyses in which the units of analysis were vast world regions (Western Eurasia, Eastern Eurasia, Insular Pacific, Africa, North America, and South America) that, on the basis of ethnographic analyses, have been identified as culturally distinct (Murdock, 1949). Region-level values on each of the five primary variables (pathogen prevalence and the four conformity measures) were computed as the means of all country-level values with each of the world regions. Although statistical power is severely limited by the small number of world regions $(n=6)$, descriptive results $(r s)$ from these region-level analyses are informative. The pathogen prevalence hypothesis is more convincingly supported if results from the region-level analyses are consistent with those from the country-level analyses.

Even if observed correlations are consistent with the pathogen prevalence hypothesis, alternative causal explanations must be considered. One possibility is a reverse causal relation: Cultural differences in conformity might be a cause (rather than a consequence) of ecological differences in pathogen prevalence. To help address this possibility, we conducted analyses employing not only a measure of historical pathogen prevalence (described above) but also a measure of contemporary pathogen prevalence, computed from a comprehensive online database documenting contemporary epidemiological conditions around the world (see Fincher \& Thornhill, 2008, for computational details and for a list of country-level contemporary pathogen prevalence values). If cultural differences are a cause (rather than a consequence) of ecological differences in pathogen prevalence, then the conformity measures should correlate more strongly with contemporary pathogen prevalence than with historical pathogen prevalence. If not - if historical pathogen prevalence is the stronger predictor of contemporary cultural outcomes - then the reverse causal explanation is less plausible.

A variety of different third-variable causal explanations must also be considered. Many other ecological and economic variables (e.g., economic wealth, agricultural mode of subsistence, disease-irrelevant dangers) have been linked, conceptually, to conformity behavior and related constructs. The pathogen prevalence hypothesis is most convincingly supported if the predicted effects of pathogen prevalence persist even when controlling for these additional variables. In the results section below, we identify plausible thirdvariable explanations and report the results of multiple regression analyses to address each alternative explanation.

Finally, we examined whether relations between pathogen prevalence and conformity are simply an epiphenomenal by-product of the previously documented relation between pathogen prevalence and collectivism (Fincher et al., 2008). For each country in our analyses, we constructed a single collectivism score based on the four measures of individualism/ collectivism examined by Fincher et al. (2008). Scores on each of these four measures were transformed into $z$ scores, and 
(after multiplying the individualism scores by -1 so as to be interpretable as collectivism score proxies instead) mean standardized collectivism scores were computed for each country. We then conducted analyses that allowed us to determine the extent to which pathogen prevalence predicted conformity when controlling for cultural differences in collectivism.

\section{Results}

Pathogen prevalence was predicted to correlate positively with mean within-country effect size and with the percentage of the population who prioritize obedience. Conversely, pathogen prevalence was predicted to correlate negatively with within-population dispositional variability and with the percentage of left-handed people in the population. Results testing these predictions are reported in Table 1.

Across all four measures, results are consistent with the pathogen prevalence hypothesis. Results from the primary analyses (in which country served as the unit of analyses) reveal statistically significant correlations in exactly the directions predicted. These correlations are all of substantial magnitude (absolute values $>.48$ ). Ancillary analyses in which world region served as the unit of analysis corroborated the country-level analyses, producing correlations of even greater magnitude (absolute values $>.67$ ). These results are consistent with the hypothesis linking ecological variability in pathogen prevalence to cultural differences in conformity pressure.

Is a reverse causal explanation plausible? To address this possibility, we compared the results of the primary analyses (employing the measure of historical pathogen prevalence) to the results of an ancillary analysis that employed the measure of contemporary pathogen prevalence instead. Correlations involving contemporary pathogen prevalence and the four conformity measures were as follows: (a) behavioral conformity effect size, $r=.34, p=.18$, (b) percentage prioritizing obedience, $r=.61, p<.0001$, (c) dispositional variability, $r=-.46, p=.006$, (d) percentage left-handed, $r=-.57$, $p=.008$. Just one of these correlations (percentage prioritizing obedience) exceeds the corresponding correlation with historical pathogen prevalence. The other three correlations are all of lower magnitude than corresponding correlations with historical pathogen prevalence. (These differences in magnitude were not significantly significant, which is not surprising given the substantial relationship between historical and contemporary pathogen prevalence, $r=.83$.) Furthermore, regression analyses were performed that included both historical and contemporary pathogen prevalence as predictors of the conformity measures. (Inference from these results is limited, of course, because of substantial multicollinearity.) For behavioral conformity, historical prevalence was a stronger predictor $(\beta=.56, t=1.54, p=.14)$ than was contemporary prevalence $(\beta=-.08, t=-0.23, p=.82)$. For percentage prioritizing obedience, contemporary prevalence
Table I. Four Tests of the Pathogen Prevalence Hypothesis: Zero-Order Correlations Between Historical Pathogen Prevalence and Four Measures of Cultural-Level Conformity Pressure

\begin{tabular}{|c|c|c|c|c|c|c|}
\hline \multirow{3}{*}{$\begin{array}{l}\text { Conformity } \\
\text { measure }\end{array}$} & \multicolumn{6}{|c|}{ Correlation with pathogen prevalence } \\
\hline & \multicolumn{3}{|c|}{ Unit of analysis: Country } & \multicolumn{3}{|c|}{$\begin{array}{c}\text { Unit of analysis: World } \\
\text { region }\end{array}$} \\
\hline & Correlation & $n$ & $p$ & Correlation & $n$ & $p$ \\
\hline $\begin{array}{l}\text { Behavioral } \\
\text { conformity } \\
\text { effect size }\end{array}$ & .49 & 17 & .04 & .88 & 6 & .02 \\
\hline $\begin{array}{c}\text { Percentage } \\
\text { prioritizing } \\
\text { obedience }\end{array}$ & .48 & 83 & $<.001$ & .67 & 6 & .14 \\
\hline $\begin{array}{l}\text { Dispositional } \\
\text { variability }\end{array}$ & -.48 & 33 & .005 & -.75 & 6 & .09 \\
\hline $\begin{array}{l}\text { Percentage } \\
\text { left-handed }\end{array}$ & -.73 & 20 & $<.001$ & -.93 & 6 & .006 \\
\hline
\end{tabular}

emerged as a stronger predictor $(\beta=.58, t=4.20, p<.001)$ than historical prevalence $(\beta=.04, t=0.27, p=.79)$. For dispositional variability, historical prevalence emerged as a stronger predictor $(\beta=-.31, t=-1.23, p=.22)$ than contemporary prevalence $(\beta=-.22, t=-0.90, p=.37)$. Similarly, for left-handedness, historical prevalence emerged as a stronger predictor $(\beta=-.94, t=-2.87, p=.01)$ than contemporary prevalence $(\beta=.24, t=0.73, p=.48)$. Thus, the historical measure is the stronger predictor in three of the four cases. Although certainly not conclusive, this pattern of relations is generally more consistent with the hypothesis that pathogen prevalence exerts a causal influence on cultural differences in conformity, compared to the opposite causal relation.

What about additional causal explanations based on correlated third variables? A variety of additional country-level variables might be expected to predict cultural differences in conformity and might plausibly be confounded with pathogen prevalence. To address the plausibility of these alternative causal explanations, we conducted a series of multiple regression analyses to test whether the hypothesized effects of pathogen prevalence persist even when statistically controlling for each of these additional variables.

In conducting these regression analyses we were attentive to the substantial inferential problem of multicollinearity. As is common in ecological studies (in which whole populations rather than individuals serve as units of analysis), countrylevel variables tend to be highly correlated. When multiple variables of this kind are entered as predictors in regression analyses, there is typically a high level of multicollinearity (Graham, 2003). The inferential consequence is a failure for individual predictors to be statistically significant even when they do, in fact, exert unique effects on the outcome variable. This inferential bias toward nonsignificance is especially problematic when sample sizes are small (Grewal, Cote, \& 
Table 2. Results of 20 Regression Analyses Testing Unique Effects of Historical Pathogen Prevalence on Each of the 4 Conformity Measures While Controlling for Each of the 5 Potential Confounding Variables

\begin{tabular}{|c|c|c|c|c|c|c|c|c|}
\hline \multirow[b]{2}{*}{ Potential confound controlled for } & \multicolumn{2}{|c|}{$\begin{array}{l}\text { Behavioral } \\
\text { conformity } \\
\text { effect size }\end{array}$} & \multicolumn{2}{|c|}{$\begin{array}{l}\text { Percentage } \\
\text { prioritizing } \\
\text { obedience }\end{array}$} & \multicolumn{2}{|c|}{$\begin{array}{l}\text { Dispositional } \\
\text { variability }\end{array}$} & \multicolumn{2}{|c|}{$\begin{array}{l}\text { Percentage } \\
\text { left-handed }\end{array}$} \\
\hline & $\beta$ & $p$ & $\beta$ & $p$ & $\beta$ & $p$ & $\beta$ & $p$ \\
\hline GDP per capita & .34 & .40 & .42 & .001 & -.57 & .02 & -.64 & .03 \\
\hline Population density & .62 & .02 & .54 & .0001 & -.45 & .01 & -.79 & .0005 \\
\hline Arable cropland & .62 & .05 & .52 & .0001 & -.40 & .05 & -.70 & .004 \\
\hline Agricultural labor force & .13 & .70 & .40 & .003 & -.47 & .09 & -.85 & .002 \\
\hline Life expectancy & .12 & .68 & .24 & .04 & -.38 & .05 & -.88 & .002 \\
\hline
\end{tabular}

Table 3. Results of 20 Regression Analyses Testing Unique Effects of 5 Potential Confounds on Each of the 4 Conformity Measures While Controlling for Historical Pathogen Prevalence

\begin{tabular}{|c|c|c|c|c|c|c|c|c|}
\hline \multirow[b]{2}{*}{ Unique effect of potential confound } & \multicolumn{2}{|c|}{$\begin{array}{l}\text { Behavioral } \\
\text { conformity } \\
\text { effect size }\end{array}$} & \multicolumn{2}{|c|}{$\begin{array}{l}\text { Percentage } \\
\text { prioritizing } \\
\text { obedience }\end{array}$} & \multicolumn{2}{|c|}{$\begin{array}{l}\text { Dispositional } \\
\text { variability }\end{array}$} & \multicolumn{2}{|c|}{$\begin{array}{l}\text { Percentage } \\
\text { left-handed }\end{array}$} \\
\hline & $\beta$ & $p$ & $\beta$ & $p$ & $\beta$ & $p$ & $\beta$ & $p$ \\
\hline GDP per capita & -.16 & .69 & -.18 & .17 & -.19 & .42 & .13 & .64 \\
\hline Population density & -.13 & .58 & -.13 & .23 & -.10 & .56 & .24 & .19 \\
\hline Arable cropland & .39 & .20 & -.04 & .72 & .17 & .39 & -.04 & .84 \\
\hline Agricultural labor force & .47 & .18 & .20 & .12 & .00 & .99 & .21 & .37 \\
\hline Life expectancy & -.57 & .06 & -.48 & .0001 & .17 & .39 & -.20 & .40 \\
\hline
\end{tabular}

Baumgartner, 2004) — as is the unavoidable case in our data set. The multicollinearity problem is also exaggerated as the number of correlated predictor variables increases. Therefore, as our primary analytic strategy we conducted a set of 20 two-predictor regression analyses in which (for each of the four conformity outcome measures) pathogen prevalence was entered as a predictor along with each potential confound individually. In the following paragraphs, we identify each potential confounding variable; relevant results are presented in Tables 2 and 3.

Hofstede (2001) suggested that economic development may have a negative influence on collectivistic value systems and their behavioral correlates such as conformity. A common indicator of economic development, gross domestic product per capita (GDP; values obtained from www.world bank.org for the year 2005), was significantly correlated with two of the four conformity measures examined here (percentage prioritizing obedience and percentage left-handed, $r \mathrm{~s}=-.43$ and .58 respectively, $p \mathrm{~s}<.01)$. Do the predicted country-level effects of pathogen prevalence persist even when controlling for GDP? We conducted regression analyses on each of the four conformity measures, including both GDP and historical pathogen prevalence as predictors. Results across all four analyses revealed no unique effects of GDP (see Table 3). In contrast, pathogen prevalence exerted statistically significant unique effects on three of the four conformity measures (see Table 2).

Population density has also been identified as a predictor of conformity-relevant constructs such as cultural tightness (Gelfand et al., 2006). However, none of the four conformity measures was significantly correlated with country-level population density ( $p s>.25$; population density values were obtained from the CIA World Factbook and normalized with a $\log$ transformation). Regression analyses on each of the four conformity measures, including both population density and pathogen prevalence as predictors, revealed minimal unique effects of population density; by comparison, the unique predictive effects of pathogen prevalence were significant on all four measures (see Table 2).

Berry $(1967,1979)$ suggested that cultural conformity pressures are likely to be more pronounced within agricultural societies. To address the potential confound between agriculture and pathogen prevalence, we conducted analyses on two different indicators of agricultural activity within countries: (a) arable cropland per capita and (b) percentage of the labor force employed in agricultural jobs (values on both variables obtained from www.nationmaster.com). Arable cropland did not correlate significantly with any of the conformity measures, nor was it a unique predictor of any measure when entered along with pathogen prevalence as a 
Table 4. Results of Multiple Regression Analyses Testing Unique Effects When Including Historical Pathogen Prevalence and All Five Potential Confounds Simultaneously

\begin{tabular}{|c|c|c|c|c|c|c|c|c|}
\hline \multirow[b]{2}{*}{ Predictor variable } & \multicolumn{2}{|c|}{$\begin{array}{l}\text { Behavioral } \\
\text { conformity } \\
\text { effect size }\end{array}$} & \multicolumn{2}{|c|}{$\begin{array}{l}\text { Percentage } \\
\text { prioritizing } \\
\text { obedience }\end{array}$} & \multicolumn{2}{|c|}{$\begin{array}{l}\text { Dispositional } \\
\text { variability }\end{array}$} & \multicolumn{2}{|c|}{$\begin{array}{l}\text { Percentage } \\
\text { left-handed }\end{array}$} \\
\hline & $\beta$ & $p$ & $\beta$ & $p$ & $\beta$ & $p$ & $\beta$ & $p$ \\
\hline Pathogen prevalence & .55 & .50 & .30 & .05 & -.65 & .05 & -.72 & .10 \\
\hline GDP per capita & .03 & .97 & .01 & .94 & -1.07 & .02 & .47 & II \\
\hline Population density & .27 & .77 & -.26 & .07 & .04 & .89 & .40 & .45 \\
\hline Arable cropland & .69 & .53 & -.20 & .15 & .23 & .41 & .32 & .50 \\
\hline Agricultural labor force & -.47 & .62 & .08 & .63 & .12 & .74 & .18 & .67 \\
\hline Life expectancy & -.84 & .48 & -.33 & .07 & 1.03 & .01 & -.32 & .40 \\
\hline
\end{tabular}

predictor in regression analyses; by comparison, pathogen prevalence remained a significant predictor of all four conformity variables even when controlling for arable land (see Table 2). The agricultural labor force measure did show significant zero-order correlations with three of the four conformity measures. However, when entered along with pathogen prevalence in regression analyses, agricultural labor force did not uniquely predict any of the four measures; by comparison, pathogen prevalence remained a significant predictor of two of the four measures (and marginally significant for a third measure) when controlling for agricultural labor force (see Table 2).

Individual conformity behavior increases under circumstances in which death and danger are salient (Griskevicius et al., 2006; Renkema, Stapel, \& Van Yperen, 2008). Consequently, cultural conformity pressures might be predicted by the prevalence of threats that have nothing to do with disease at all (e.g., starvation, catastrophic weather, war). As a broad proxy for threats in general, we obtained countrylevel life expectancy scores from the World Health Organization (www.who.int). Life expectancy correlated significantly with three of the four conformity measures; however, given that reduced life expectancy is a causal consequence of pathogen prevalence, these correlations are relatively uninformative. Regression analyses on each of the four conformity measures, including both life expectancy and pathogen prevalence as predictors, revealed significant unique effects of life expectancy on only one conformity measure and a marginally significant effect $(p=.06)$ on another. By comparison, the unique effects of pathogen prevalence remained significant on three of the four measures (see Table 2).

In summary, even when controlling for a series of 5 potential confounding variables, pathogen prevalence remained a significant predictor of the 4 conformity outcome variables in 16 of 20 multiple regression analyses (see Table 2). In contrast, potential confounding variables exerted unique predictive effects in only 1 of the 20 analyses when controlling for pathogen prevalence (see Table 3).
In addition to the analyses above, we conducted four follow-up regression analyses (corresponding to each of the four conformity outcome variables) in which we included historical pathogen prevalence as a predictor simultaneously with all five potential confounds. The results of these four regression analyses (one for each of the conformity variables) are summarized in Table 4. Statistical inference is especially limited for these analyses, given the significant bias toward nonsignificance that accompanies high levels of multicollinearity (and is exaggerated by reductions in degrees of freedom). It is notable, therefore, that even under these analytic circumstances, historical pathogen prevalence remained a significant predictor of two of the outcome variables (dispositional variability and the percentage prioritizing obedience) and a marginally significant predictor of a third (percentage left-handed). In summary, even under conditions in which there is a strong statistical bias against obtaining statistically significant effects of individual predictors, there remains evidence that pathogen prevalence is a unique predictor of crosscultural variability in conformity pressure.

A final set of analyses tested whether the relation between pathogen prevalence and conformity persisted even when controlling for cultural differences in collectivism. (The aggregate collectivism score correlated significantly with behavioral conformity effect size, percentage prioritizing obedience, and percentage left-handed $[r \mathrm{~s}=.59, .32$, and -.72 , respectively, $p s<.02$ ] and marginally with dispositional variability $[r=.29, p=.10]$.) Regression analyses were conducted on each of the four conformity measures, including both pathogen prevalence and the aggregate collectivism index as predictors. Results revealed no significant unique predictive effects of collectivism $(\beta s<.36, p s>.20)$. By comparison, the unique predictive effects of pathogen prevalence remained significant on two outcome variables: the value placed on obedience $(\beta=.48, p=.002)$ and dispositional variability ( $\beta=-.78, p=.01)$. Moreover, pathogen prevalence emerged as a stronger (albeit nonsignificant) unique predictor than collectivism on the remaining two conformity measures. Thus, although there is undoubtedly a strong empirical relation 
between collectivism and conformity (Bond \& Smith, 1996), these results suggest that the relation between pathogen prevalence and conformity cannot be dismissed as a mere behavioral by-product of the previously documented relation between pathogen prevalence and collectivism.

\section{Discussion}

The results can be summarized as follows: Ecological variability in pathogen prevalence predicts worldwide crosscultural variability in conformity. This relationship is obtained consistently across four methodologically diverse indicators of cultural conformity pressures. This relationship is also obtained regardless of whether countries or larger cultural regions are treated as the unit of analysis. The predictive effects of historical pathogen prevalence are generally stronger than the effects of contemporary pathogen prevalence. Moreover, relationships between historical pathogen prevalence and conformity measures persist even when controlling for a variety of additional variables that might plausibly be associated with cultural differences in conformity (conversely, predictive effects of these other variables largely disappeared when controlling for pathogen prevalence). These results argue against alternative causal explanations and thus support the hypothesis that cultural variability in conformity is a consequence, at least in part, of ecological variability in the prevalence of disease-causing pathogens.

The consistent pattern of effects across all four measures is notable not just because these measures are methodologically diverse but also because (aside from their common link to cultural conformity pressures) they are conceptually diverse as well. These findings may therefore have additional implications that are not specific to conformity (e.g., implications for research on personality variation, handedness, etc.). The left-handedness finding is perhaps particularly notable given that, within the handedness literature, there is evidence of a causal process that might be expected to produce the exact opposite relation with pathogen prevalence. Natural deviations from modal handedness appear to be attributable, in part, to developmental instabilities during early fetal development (e.g., Gangestad \& Yeo, 1994). Greater levels of fetal developmental instability would be expected under conditions of greater maternal stress of the sort associated with infectious diseases. This implies that under conditions of higher pathogen prevalence, the percentage of left-handers should be relatively higher-and not lower as documented by our results. Indeed, it is possible that there are more naturally born left-handers in such high-pathogen environments but that this effect is small and completely overwhelmed by the considerable conformity pressures evident within these same environments - conformity pressures that compel naturally born left-handers to throw right-handed and to write right-handed and, ultimately, to self-identify with the righthanded majority.
Although the results reported here are consistent with a causal influence of pathogen prevalence on cultural conformity pressures, causal interpretation of these results is logically constrained by a limitation common to cross-cultural investigations: The methods are necessarily correlational (see Cohen, 2007, for an extensive discussion on this issue). It is impossible to draw a completely confident causal conclusion. Still, it is notable that the results of ancillary analyses argue against the most plausible alternative causal explanations. Furthermore, although the causal hypothesis cannot be rigorously confirmed on the basis of these empirical results alone, a broader set of scientific findings attests to the powerful causal influence of pathogens on the actions of individuals and on the defining features of populations (e.g., Zuk, 2007). Most of this work focuses on nonhuman animals, of course, but there is little logical reason to expect human populations to be exempt from the substantial influence of diseasecausing pathogens.

Our analyses focused on measures that assess conformity pressure in general rather than on measures that assess conformity within specific behavioral contexts. It is plausible that the relation between pathogen prevalence and conformity might be especially pronounced in behavioral domains that are most especially strongly linked to pathogen transmission (such as food preparation, personal hygiene, and sexual behavior). Future research, using more nuanced measures of context-specific conformity pressure, will be required to explore this possibility.

It will also be important for future research to attend closely to possible mechanisms that might have accounted for any causal relation between pathogen prevalence and cultural conformity pressure. These cultural differences could emerge through a variety of profoundly different mechanisms. For example, these differences could emerge and persist as a result of cultural transmission processes. Different ecological circumstances impose different selective pressures on the cultural information (e.g., behavioral expectations) that is transmitted within social groups (Berger \& Heath, 2005; Richerson \& Boyd, 2005). Behavioral expectations promoting conformity may be more readily communicated, taught, and learned in ecologies characterized by high pathogen prevalence. Conversely, where pathogens are less prevalent, people may be more likely to transmit information promoting tolerance for nonconformity.

In addition to these effects on cultural transmission, pathogen prevalence may also influence genetic transmission. Results of behavioral genetics research on related constructs (e.g., openness, collectivism, and the clinical trait of "spontaneous nonconformity"; Blonigen, Carlson, Krueger, \& Patrick, 2003; Bouchard \& McGue, 2003; Jang, Livesley, \& Vemon, 1996) suggest that there may be some genetically heritable predisposition toward conformity. If so, then specific alleles associated with conformity may have been differentially selected for within populations characterized by 
relatively high levels of pathogen prevalence, whereas alleles associated with nonconformity may have been more likely to proliferate within populations characterized by relatively low levels of pathogen prevalence. One plausible candidate for such an allele may be the 5-HTTLPR polymorphic region of the SLC6A4 serotonin transporter gene. The short version of this polymorphism is associated with avoidant behavioral tendencies and occurs in different frequencies across different cultural populations, and, in cross-national analyses, these population-level gene frequencies are significantly correlated with cultural variation along the individualism/collectivism dimension (Chiao \& Blizinsky, 2010). In fact, Chiao and Blizinsky (2010) report that the population-level frequency of 5-HTTLPR alleles partially mediates the statistical relationship between pathogen prevalence and collectivism. This provocative finding substantiates the possibility that genetic selection mechanisms might partly account for a causal relationship between pathogen prevalence and cultural conformity pressures.

A third plausible explanation focuses on the developmental processes through which genotypes create phenotypes. Many phenotypic differences result not from differences in genes per se but rather from differences in the developmental expression of common genes (Ridley, 2003). Gene expression is adaptively influenced by the ecological circumstances within which individual organisms develop (Gangestad et al., 2006). Within ecologies characterized by higher pathogen prevalence, genes promoting conformist dispositional tendencies may be expressed to a greater degree than under low pathogen prevalence conditions. Consistent with this conjecture is experimental evidence showing that, among nonhuman animals, prenatal exposure to corticosteroids (produced by immunological responses to pathogen infection) is associated with the development of more cautious behavioral tendencies (Curno, Behnke, McElligott, Reader, \& Barnard, 2009; Takahashi, Haglin, \& Kalin, 1992).

A fourth kind of explanatory mechanism is more fundamentally social psychological in nature and focuses on the effects of immediate perceptual contexts on social behavior. Individuals' behavioral tendencies toward conformity - and their cognitions bearing on those behaviors - vary as a function of perceptual cues indicating the presence of threats in their immediate social context (Griskevicius et al., 2006). It is plausible, therefore, that just as perceptual information indicating the imminent threat of infectious disease causes individuals to be more xenophobic and less extraverted (Faulkner et al., 2004; Mortensen et al., 2010), this perceptual information may also incline individuals to favor less risky, more conformist behavioral strategies. Under ecological conditions in which disease-connoting perceptual information is more chronically salient (conditions of high pathogen prevalence), the implication is a chronically greater inclination toward conformity.
These are four very different kinds of explanatory mechanisms, operating at different levels of analysis. Each mechanism is plausible on logical grounds. And given that these explanatory mechanisms are conceptually independent, these causal mechanisms are not mutually exclusive. If pathogen prevalence did play a role in the emergence of cultural differences in conformity (as the empirical results suggest), this effect may well have resulted from multiple causal mechanisms operating simultaneously on genes, individuals, and cultures.

\section{Declaration of Conflicting Interests}

The authors declared no potential conflicts of interests with respect to the authorship and/or publication of this article.

\section{Financial Disclosure/Funding}

This research was supported by a Canada Graduate Scholarship (awarded to D.R.M.) and by a Standard Research Grant (awarded to M.S.) from the Social Sciences and Humanities Research Council of Canada.

\section{References}

Berger, J. A., \& Heath, C. (2005). Idea habitats: How the prevalence of environmental cues influences the success of ideas. Cognitive Science, 29, 195-221.

Berry, J. W. (1967). Independence and conformity in subsistencelevel societies. Journal of Personality and Social Psychology, 7, 415-418.

Berry, J. W. (1979). A cultural ecology of social behavior. In L. Berkowitz (Ed.), Advances in experimental social psychology (Vol. 12, pp. 177-206). New York, NY: Academic Press.

Billing, J., \& Sherman, P. W. (1998). Antimicrobial functions of spices: Why some like it hot. Quarterly Review of Biology, 73, 3-49.

Blonigen, D. M., Carlson, S. R., Krueger, R. F., \& Patrick, C. J. (2003). A twin study of self-reported psychopathic personality traits. Personality and Individual Differences, 35, 179-197.

Bond, R., \& Smith, P. B. (1996). Culture and conformity: A metaanalysis of studies using Asch's $(1952,1956)$ line judgment task. Psychological Bulletin, 119, 111-137.

Bouchard, T. J., Jr., \& McGue, M. (2003). Genetic and environmental influences on human psychological differences. Journal of Neurobiology, 54, 4-45.

Chiao, J. Y., \& Blizinsky, K. D. (2010). Culture-gene coevolution of individualism-collectivism and the serotonin transporter gene. Proceedings of the Royal Society B, 277, 529-537.

Cohen, D. (2001). Cultural variation: Considerations and implications. Psychological Bulletin, 127, 451-471.

Cohen, D. (2007). Methods in cultural psychology. In S. Kitayama \& D. Cohen (Eds.), Handbook of cultural psychology (pp. 196-236). New York, NY: Guilford.

Curno, O., Behnke, J. M., McElligott, A. G., Reader, T., \& Barnard, C. J. (2009). Mothers produce less aggressive sons with altered immunity when there is a threat of disease during pregnancy. Proceedings of the Royal Society B, 276, 1047-1054. 
Duncan, L. A., \& Schaller, M. (2009). Prejudicial attitudes toward older adults may be exaggerated when people feel vulnerable to infectious disease: Evidence and implications. Analyses of Social Issues and Public Policy, 9, 97-115.

Fagard, J., \& Dahmen, R. (2004). Cultural influences on the development of lateral preferences: A comparison between French and Tunisian children. Laterality, 9, 67-78.

Faulkner, J., Schaller, M., Park, J. H., \& Duncan, L. A. (2004). Evolved disease-avoidance mechanisms and contemporary xenophobic attitudes. Group Processes and Intergroup Behavior, 7, 333-353.

Fincher, C. L., \& Thornhill, R. (2008). Assortative sociality, limited dispersal, infectious disease and the genesis of the global pattern of religion diversity. Proceedings of the Royal Society $B, 275,2587-2594$.

Fincher, C. L., Thornhill, R., Murray, D. R., \& Schaller, M. (2008). Pathogen prevalence predicts human cross-cultural variability in individualism/collectivism. Proceedings of the Royal Society $B, 275,1379-1385$.

Gangestad, S. W., Haselton, M. G., \& Buss, D. M. (2006). Evolutionary foundations of cultural variation: Evoked culture and mate preferences. Psychological Inquiry, 17, 75-95.

Gangestad, S. W., \& Yeo, R. A. (1994). Parental handedness and relative hand skill: A test of the developmental instability hypothesis. Neuropsychology, 8, 572-578.

Gelfand, M. J., Nishii, L. H., \& Raver, J. L. (2006). On the nature and importance of cultural tightness-looseness. Journal of Applied Psychology, 91, 1225-1244.

Graham, M. H. (2003). Confronting multicollinearity in ecological multiple regression. Ecology, 84, 2809-2815.

Grewal, R., Cote, J. A., \& Baumgartner, H. (2004). Multicollinearity and measurement error in structural equation models: Implications for theory testing. Marketing Science, 23, 519-529.

Griskevicius, V., Goldstein, N. J., Mortensen, C. R., Cialdini, R. B., \& Kenrick, D. T. (2006). Going along versus going alone: When fundamental motives facilitate strategic (non)conformity. Journal of Personality and Social Psychology, 91, 281-294.

Henrich, J. (2003). Cultural group selection, coevolutionary processes and large-scale cooperation. Journal of Economic Behavior and Organization, 53, 3-35.

Hofstede, G. (2001). Culture's consequences (2nd ed.). Thousand Oaks, CA: Sage.

Hurtado, A., Frey, M., Hill, K., Hurtado, I., \& Baker, J. (2008). The role of helminthes in human evolution: Implications for global health in the 21st century. In S. Elton \& P. O'Higgins (Eds.), Medicine and evolution: Current applications, future prospects (pp. 151-178). New York, NY: Taylor \& Francis.

Jang, K. L., Livesley, W. J., \& Vemon, P. A. (1996). Heritability of the Big Five personality dimensions and their facets: A twin study. Journal of Personality, 64, 577-592.

Kavaliers, M., \& Colwell, D. D. (1995). Discrimination by female mice between the odours of parasitized and non-parasitized males. Proceedings of the Royal Society B, 261, 31-35.
Kiesecker, J. M., Skelly, D. K., Beard, K. H., \& Preisser, E. (1999). Behavioral reduction of infection risk. Proceeding of the National Academy of Sciences, 96, 9165-9168.

Kitayama, S., \& Bowman, N. A. (2010). Cultural consequences of voluntary settlement in the frontier: Evidence and implications. In M. Schaller, A. Norenzayan, S. J. Heine, T. Yamagishi, \& T. Kameda (Eds.), Evolution, culture, and the human mind (pp. 205-227). New York, NY: Psychology Press.

Kitayama, S., Ishii, K., Imada, T., Takemura, K., \& Ramaswamy, J. (2006). Voluntary settlement and the spirit of independence: Evidence from Japan's "northern frontier." Journal of Personality and Social Psychology, 91, 369-384.

Letendre, K., Fincher, C. L., \& Thornhill, R. (2010). Does infectious disease cause global variation in the frequency of intrastate armed conflict and civil war? Biological Reviews, 85, 669-683.

Low, B. S. (1990). Marriage systems and pathogen stress in human societies. American Zoologist, 30, 325-339.

McCrae, R. R. (2002). NEO-PI-R data from 36 cultures: Further intercultural comparisons. In R. R. McCrae \& J. Allik (Eds.), The five-factor model of personality across cultures (pp. 105-126). New York, NY: Kluwer Academic/Plenum.

Mortensen, C. R., Becker, D. V., Ackerman, J. M., Neuberg, S. L., \& Kenrick, D. T. (2010). Infection breeds reticence: The effects of disease salience on self-perceptions of personality and behavioral tendencies. Psychological Science, 21, 440-447.

Murdock, G. P. (1949). Social structure. New York, NY: Macmillan.

Murray, D. R., \& Schaller, M. (2010). Historical prevalence of disease within 230 geopolitical regions: A tool for investigating origins of culture. Journal of Cross-Cultural Psychology, 41, 99-108.

Navarrete, C. D., \& Fessler, D. M. T. (2006). Disease avoidance and ethnocentrism: The effects of disease vulnerability and disgust sensitivity on intergroup attitudes. Evolution and Human Behavior, 27, 270-282.

Navarrete, C. D., Fessler, D. M. T., \& Eng, S. J. (2007). Elevated ethnocentrism in the first trimester of pregnancy. Evolution and Human Behavior, 28, 60-65.

Oaten, M., Stevenson, R. J., \& Case, T. I. (2009). Disgust as a diseaseavoidance mechanism. Psychological Bulletin, 135, 303-321.

Park, J. H., Faulkner, J., \& Schaller, M. (2003). Evolved diseaseavoidance processes and contemporary anti-social behavior: Prejudicial attitudes and avoidance of people with physical disabilities. Journal of Nonverbal Behavior, 27, 65-87.

Park, J. H., Schaller, M., \& Crandall, C. S. (2007). Pathogenavoidance mechanisms and the stigmatization of obese people. Evolution and Human Behavior, 28, 410-414.

Perelle, I. B., \& Ehrman, L. (1994). An international study of human handedness: The data. Behavior Genetics, 24, 217-227.

Porac, C., \& Martin, W. L. B. (2007). A cross-cultural comparison of pressures to switch left-handed writing: Brazil versus Canada. Laterality, 12, 273-291.

Quinlan, R. J. (2007). Human parental effort and environmental risk. Proceedings of the Royal Society B, 274, 121-125. 
Renkema, L. J., Stapel, D. A., \& Van Yperen, N. W. (2008). Go with the flow: Conformity in the face of existential threat. European Journal of Social Psychology, 38, 747-756.

Richerson, P. J., \& Boyd, R. (2005). Not by genes alone: How culture transformed human evolution. Chicago, IL: University of Chicago Press.

Ridley, M. (2003). The agile gene. New York, NY: HarperCollins.

Ross, M. H., \& Homer, E. (1976). Galton's problem in crossnational research. World Politics, 29, 1-28.

Schaller, M., \& Duncan, L. A. (2007). The behavioral immune system: Its evolution and social psychological implications. In J. P. Forgas, M. G. Haselton, \& W. von Hippel (Eds.), Evolution and the social mind: Evolutionary psychology and social cognition (pp. 293-307). New York, NY: Psychology Press.

Schaller, M., \& Murray, D. R. (2008). Pathogens, personality, and culture: Disease prevalence predicts worldwide variability in sociosexuality, extraversion, and openness to experience. Journal of Personality and Social Psychology, 93, 212-221.

Schaller, M., \& Murray, D. R. (2010). Infectious diseases and the evolution of cross-cultural differences. In M. Schaller, A. Norenzayan, S. J. Heine, T. Yamagishi, \& T. Kameda
(Eds.), Evolution, culture, and the human mind (pp. 243-256). New York, NY: Psychology Press.

Schaller, M., \& Park, J. H. (in press). The behavioral immune system (and why it matters). Current Directions in Psychological Science.

Sherman, P. W., \& Billing, J. (1999). Darwinian gastronomy: Why we use spices. Bioscience, 49, 453-463.

Takahashi, L. K., Haglin, C., \& Kalin, N. H. (1992). Prenatal stress potentiates stress-induced behavior and reduces the propensity to play in juvenile rats. Physiology \& Behavior, 51, 319-323.

Thornhill, R., Fincher, C. L., \& Aran, D. (2009). Parasites, democratization, and the liberalization of values across contemporary countries. Biological Reviews, 84, 113-131.

Triandis, H. C. (1995). Individualism \& collectivism. Oxford, UK: Westview.

Van de Vliert, E. (2009). Climate, affluence, and culture. Cambridge, UK: Cambridge University Press.

Wolfe, N. D., Dunavan, C. P., \& Diamond, J. (2007). Origins of major human infectious diseases. Nature, 447, 279-283.

Zuk, M. (2007). Riddled with life: Friendly worms, ladybug sex, and the parasites that make us who we are. Orlando, FL: Harcourt. 